\title{
Influence of Self-Efficacy as a Mediator on Time Management and Students' Performance Relationship in Malaysian Online Distance Learning Institutions.
}

\author{
Zahir Osman, Wardah Mohamad, Ratna Khuzaimah Mohamad, Liana Mohamad, and \\ Tuan Fatma Tuan Sulaiman \\ Cluster of Business Management, Open University Malaysia, Bangi, Selangor, Malaysia
}

\begin{abstract}
The main purpose of this study is to develop a mediating effect understanding of self-efficacy on time management and students' performance relationship in Malaysian online distance learning institutions. A model was developed and later tested by adopting the partial Least Square (PLS) procedure on data collected from a survey that yielded 210 usable questionnaires. The findings showed that time management enhanced self-efficacy in Malaysian online distance learning institutions. It was also revealed that self-efficacy partially mediates the relationship between time management and students' performance. In future, more research needs to be carried out to explore the role of self-efficacy in Malaysian online distance learning institutions. It is important to do the study utilizing experimental design by capturing longitudinal data in Malaysian online distance learning institutions using robust measures. The findings imply that the relationship between self-efficacy and attrition rate may reside in self-efficacy's influence on students' performance, and that self-efficacy plays a crucial function within the Malaysian online distance learning institutions. This study uses Smartpls 2.0 and SPSS 18.0 to test the hypothesis and analyze respondents' profile respectively.
\end{abstract}

\section{Keywords: Time Management, Self-Efficacy, Students' Performance, Online Distance Learning}

\section{INTRODUCTION}

Academic achievement is the main objective amongst students who pursue their tertiary education. A tertiary education institution's performance normally will be measured by its ability to retain its students and the students' results. Thus, if the students' failure rate is too high, it will give the higher education institution a negative image and thus affects its performance. In the past decades, much research has focused on students' performance. However, not many have conducted studies on online distance learning students' performance. The real contributing reason to the failure of many

online distance learning students remain unclear despite the many efforts which have been taken up to assist them. In addition, a high failure rate among students will further affect an institution's standing in society because of the recent government decision to increase the rate of enrolment and widen access to education, while at the same time reducing financial support to the tertiary education sector. The main aim of this study is to probe how self-efficacy mediates the relationship between time management and students' performance in Malaysian online distance learning institutions and therefore put forward a perspective of how these factors influence the performance of the students in their studies. This study was quantitative in nature, filling in the current gap regarding this issue in the current online disctance learning education literature. The findings will guide academics on how to motivate their students to manage their time and increase their performance.

\section{LITERATURE REVIEW}

\section{Underpinning Theory}

The self-efficacy theory lies at the heart of Bandura's social cognitive theory [1], which highlights the function of observational learning and social experience in personality development. The important notion in social cognitive theory is that a person's actions and reactions, as well as social behaviors and cognitive processes, in most situations are affected by the actions that a person has viewed in others. Since self-efficacy is developed from external experiences and selfperception; and is dominant in shaping the outcome of many occurrences; it is a vital aspect of social cognitive theory. Self-efficacy is a person's belief in his or her own ability to succeed in specific situations or accomplish a task. Bandura's theory states that people with strong self-efficacy are those

\footnotetext{
Corresponding Author: Zahir Osman, Open University Malaysia, Bangi, Selangor, Malaysia, 03-89135516
} 
who consider that they can perform better and are inclined to view tough tasks as something to be mastered rather than something to be kept away from.

\section{Conceptual Development}

Over the years, there has been a major change experienced by online distance learning [2]. The rapid developments of the internet and other technologies have resulted in online teaching and learning being incorporated into a university's usual practice. It has also given distance education a new appeal [3]. According to Bates [4], online learning is expected to be a distance education subcategory that uses the World Wide Web and internet. Online distance learning has been very popular in recent years and is being utilized by many education institutions in different countries in order to give prospects something new and meet the desires of the escalating student population [5]. Time management can be defined by how an individual organizes, schedules and budgets his or her time in order to generate effective work and increase productivity. It is based on priority - how an individual allocates and distributes his time towards competing tasks. Gerald [6] described time management as a principle, skills, tools, systems and practices that are combined in an effort to ensure that the individual achieve better time value, which will eventually improve his quality of life. Studies have shown that students who practice time management managed to perform better in academia [7]. According to Argarwal [8], time management is normally related to personal problems and if the individual intuitively realizes what is right, then he would not have to worry. In higher learning institutions, students' grades usually depend on a range of tasks completed which have various deadlines, priorities and lengths. Bandura [9] termed self efficacy as the confidence in an individual and the ability to completely get a specific task done successfully. Self-efficacy beliefs are vitally significant elements to ensure a person's ability to put effort on tasks and constantly deal with difficulties. A person with a high self-efficacy will put more attempts to finish given tasks and not easily surrender even though the tasks can be difficult. On the other hand, individuals with a low self-efficacy can easily quit without putting extra effort most of the time. As Bandura [9] suggested, a person's beliefs about his capabilities form the person's self-efficacy. Selfefficacy foresees intellectual performance as far better than skills alone and that academic performance is directly influenced via cognition. Many studies have revealed that self-efficacy plays a role of mediator with regards to learning and students' performance. Moustafa \& Sudhir [10] in their study on undergraduate students found that self-efficacy played a partial mediating effect on the relationship between perceived academic climate and academic performance. Meliha Canpolat A. [10] revealed that self-efficacy is a mediator that positively and significantly mediates the relationship between class climates and goal orientation when conducting the study on primary school students. Raafat \& Dennis [11] suggested that self-efficacy significantly and positively mediates the relationship between computer anxieties on perceived ease of use when studying on online learning university students.

\section{Research Hypotheses}

The following are the research hypotheses tested in this study:

H1: There is a positive and significant relationship between time management and student performance.

$\mathrm{H} 2$ : There is a positive and significant relationship between time management and self-efficacy.

H3: There is a positive and significant relationship between self-efficacy and student performance.

H4: There is a positive and significant mediating effect of self-efficacy on time management and student's performance relationship.

\section{METHODOLOGY}

This study consists of 15 observed variables constitute the measurement of exogenous independent variable of time management 5 items. The mediating variable of self-efficacy consists of 5 items, and dependent variable of student performance, 5 items. The scaling utilized in this study is the 5-point Likert scale of 1- strongly disagree, 2-disagree, 3-neutral, 4-agree and 5strongly agree. In this study, questionnaires were adopted to collect data. Online distance learning students in Klang Valley who are studying in the diploma, bachelor and postgraduate programmes were the main respondents in the study. From the 300 questionnaires given out, 226 were returned. This made up a response rate of $75.3 \%$. In view of that, the rate of response is adequate for SEM analysis. After data screening process, there are a total of 210 clean data sets to be used for further analysis

\section{DATA ANALYSIS}

Partial Least Squares (PLS) [12] [13] was used to evaluate the models. First, construct's validity and reliability were evaluated. The average variance 
extracted (AVE), the AVE square root, composite reliability; $\mathrm{R}^{2}$, Cronbach's Alpha and communality of each construct were computed. Construct validity was acquired by first evaluating Cronbach's Alpha for individual construct. The results are depicted in Table 1 . Mediating effects are the result of two relationships; between the independent variable and the mediator, and between the mediator and the dependent variable. The mediating effect was analyzed by using PROCESS by Hayes [14] by utilizing the application of bootstrapping technique.

Figure 1: Direct Path Coefficient

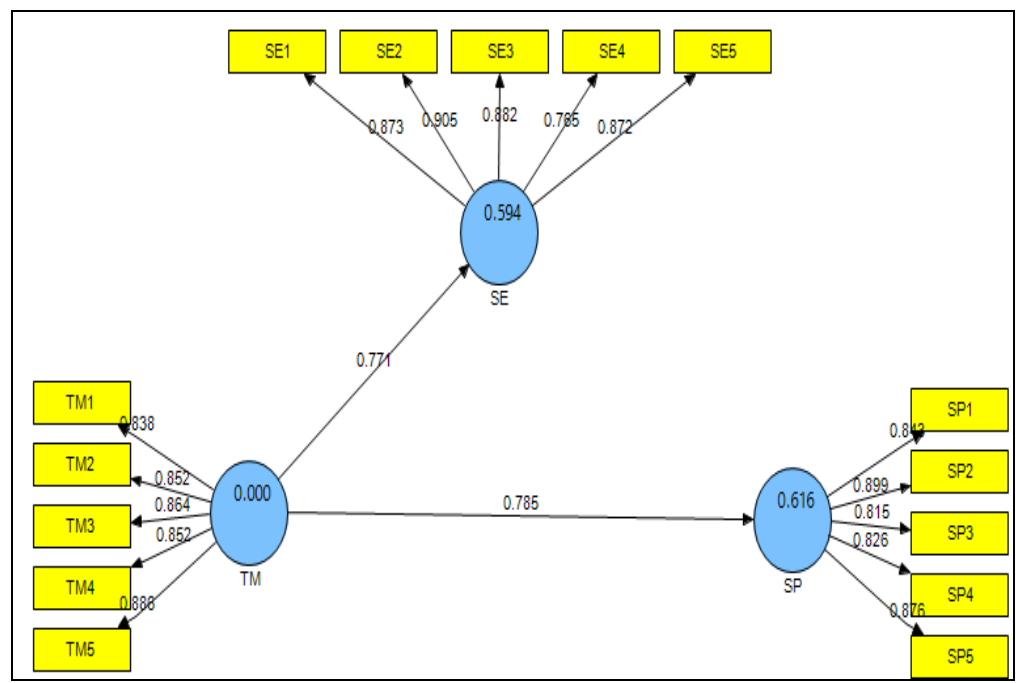

Figure 2: Indirect Path Coefficient

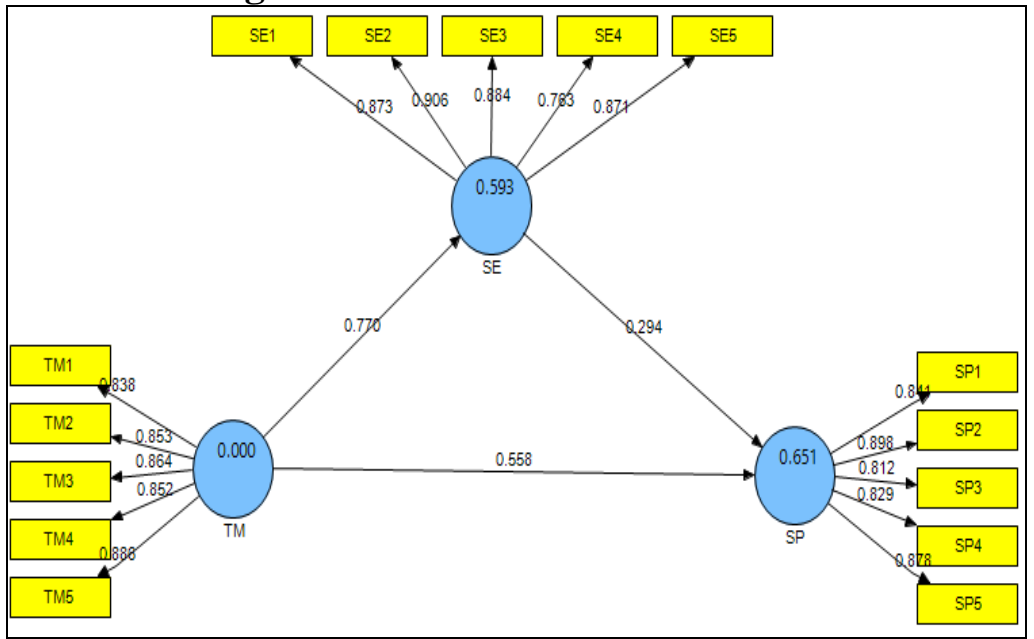

All the three constructs show higher Cronbach's Alpha which is higher than suggested, 0.7 [15]. Subsequently, all constructs were evaluated within the model by adopting PLS assessment to acquire each construct's Average Variance Extracted (AVE), composite reliability and communality. All constructs showed higher than the minimum needed for each parameter [16] [17]). Then, each construct had its AVE square root extracted to estimate construct dimensionality [18]. The result obtained used as the indication when all constructs correlated and each correlation weight within the two constructs, has to be lesser than the AVE square root as depicted in Table 2.

Table 1: Construct Validity \& Reliability

\begin{tabular}{lcrrccc}
\hline & AVE & AVEsqrt & \multicolumn{1}{c}{ Com. Rel. } & R-square & C. Alpha & Comm \\
\hline SE & 0.741 & 0.861 & 0.934 & 0.593 & 0.911 & 0.741 \\
SP & 0.726 & 0.852 & 0.930 & 0.651 & 0.906 & 0.726 \\
TM & 0.738 & 0.859 & 0.934 & 0.000 & 0.911 & 0.738 \\
\hline
\end{tabular}


Table 2: Variable Correlation Matrix based on \& AVE square Root

\begin{tabular}{lccc}
\hline & SE & SP & TM \\
\hline SE & $\mathbf{0 . 8 6 1}$ & & \\
SP & 0.7242 & $\mathbf{0 . 8 5 2}$ & \\
TM & 0.7703 & 0.785 & $\mathbf{0 . 8 5 9}$ \\
\hline
\end{tabular}

There is a present of convergent validity as shown by figure 2 , where each loading for each indicator shows greater than 0.7 , suggesting that the indicators add more variance to their respective variable than with error variance. The correlation of all constructs achieved the lower value than AVE's square root. The present of discriminant validity has been confirmed by the cross loading as depicted by table 3 . It indicates strong loading values to the corresponding latent variable and low loading values to other variables. The relationship between AVE square roots values and the correlations among first-order latent constructs embrace the similar conclusion (Table 2).

Table 3: Cross Loading

\begin{tabular}{llll}
\multicolumn{4}{c}{ Table 3: Cross Loading } \\
\hline & SE & SP & TM \\
\hline SE1 & $\mathbf{0 . 8 7 3}$ & 0.625 & 0.688 \\
SE2 & $\mathbf{0 . 9 0 6}$ & 0.644 & 0.672 \\
SE3 & $\mathbf{0 . 8 8 4}$ & 0.657 & 0.662 \\
SE4 & $\mathbf{0 . 7 6 3}$ & 0.548 & 0.607 \\
SE5 & $\mathbf{0 . 8 7 1}$ & 0.637 & 0.683 \\
SP1 & 0.609 & $\mathbf{0 . 8 4 1}$ & 0.679 \\
SP2 & 0.663 & $\mathbf{0 . 8 9 9}$ & 0.744 \\
SP3 & 0.501 & $\mathbf{0 . 8 1 2}$ & 0.594 \\
SP4 & 0.659 & $\mathbf{0 . 8 2 9}$ & 0.642 \\
SP5 & 0.639 & $\mathbf{0 . 8 7 8}$ & 0.674 \\
TM1 & 0.682 & 0.683 & $\mathbf{0 . 8 3 8}$ \\
TM2 & 0.664 & 0.628 & $\mathbf{0 . 8 5 3}$ \\
TM3 & 0.626 & 0.692 & $\mathbf{0 . 8 6 5}$ \\
TM4 & 0.617 & 0.642 & $\mathbf{0 . 8 5 2}$ \\
TM5 & 0.712 & 0.719 & $\mathbf{0 . 8 8 6}$ \\
\hline
\end{tabular}

\section{Model Evaluation}

First the direct path from time management to selfefficacy and student performance was assessed. Both relationship found to be significant and the path coefficients are 0.770 and 0.785 respectively (refer to Figure 1). Then, self-efficacy was introduced as a mediator between time management and student performance (refer to Figure 2). The mediating effect will exist if the direct path coefficient between the independent variable and dependent variable is reduced when the indirect path through the mediator is established in the model. The direct path is evaluated without the presence of mediator. The direct path standardized beta was 0.785 and change to 0.558 after the introduction of self-efficacy as a mediator. The relationship between time management and student performance has decreased by the amount of 0.212 which represent $27.53 \%$ of the direct effect. This indicates that the indirect effect of time management to student performance with the present of self-efficacy as a mediating factor is significant. PROCESS procedure by Hayes [14] utilizing the application of bootstrapping technique was used to calculate the mediating effect of selfefficacy on time management and student performance relationship. The result obtained from PROCESS indicates that the indirect effect of time management to student loyalty with the present of self-efficacy as a mediator is significant at $\mathrm{p}<.000$ where the lower level confidence level (LLCL) is 0.1499 and upper level confidence level (ULCL) is 0.4345 (Table 6). The indirect effect is significantly different from zero at $\mathrm{p}<.000$ (two tailed). With $95 \%$ confidence that, because zero is not within this interval, zero is not likely a value for the indirect effect of time management on student performance. The true indirect effect is 
estimated lies between 0.1499 and 0.4345 . Hence, the indirect path time management to self-efficacy and from self-efficacy to student performance was $0.770 * 0.294=0.226$. The confidence interval level provided by PROSESS was between 0.1499 and $0.4345, \mathrm{p}<.000$. This shows that the partial mediation effect present. Therefore, all the hypotheses are supported (Table 7).

Table 4: Direct Path Coefficient \& T-Value

\begin{tabular}{ccc}
\hline & Beta & T-Value \\
\hline TM -->SE & 0.770 & 32.06 \\
TM -->SP & 0.785 & 28.09 \\
\hline
\end{tabular}

Table 5: Indirect Path Coefficient \& T-Value

\begin{tabular}{lcc} 
& Beta & T-Value \\
\hline TM -->SE & 0.770 & 34.94 \\
TM -->SP & 0.558 & 9.92 \\
SE -->SP & 0.294 & 5.28 \\
\hline
\end{tabular}

Table 6: Significance of Indirect Effect

\begin{tabular}{llccc}
\hline & Effect & Boot SE & BootLLCI & BootULCI \\
\hline SE & 0.2766 & 0.0713 & 0.1499 & 0.4345 \\
\hline
\end{tabular}

Table 7: Hypotheses Result

\begin{tabular}{|c|c|c|c|c|}
\hline & Hypothesizes Relationship & Path & T-value & Conclusion \\
\hline $\boldsymbol{H}_{1}$ & $\begin{array}{l}\text { There is statistical significance that } \\
\text { time management predicts self- } \\
\text { efficacy }\end{array}$ & 0.770 & 34.94 & Supported \\
\hline $\mathrm{H}_{2}$ & $\begin{array}{l}\text { There is statistical significance that } \\
\text { time management predicts } \\
\text { student's performance }\end{array}$ & 0.558 & 9.92 & Supported \\
\hline $\boldsymbol{H}_{3}$ & $\begin{array}{l}\text { There is statistical significance that } \\
\text { self-efficacy predicts student's } \\
\text { performance }\end{array}$ & 0.294 & 5.28 & Supported \\
\hline & Hypothesizes Relationship & Effect & p-value & Conclusion \\
\hline $\mathrm{H}_{4}$ & $\begin{array}{l}\text { There is statistical significance that } \\
\text { self-efficacy mediates the } \\
\text { relationship between time } \\
\text { management and student's } \\
\text { performance }\end{array}$ & 0.276 & 0.000 & Supported \\
\hline
\end{tabular}

\section{DISCUSSION}

This research main purpose of this study is to establish the mediating effect of self-efficacy on time management and student performance relationship understanding in Malaysian online distance learning. This research seeks to build probable causal relationship between the constructs, which are time management, selfefficacy and student performance. In view of that, an assessment of the past study in the area of time management, self-efficacy and student performance was done. Based on initial findings of academic studies, the model was developed and it shows that time management has a positive and significant direct effect on self-efficacy furthermore, from the same model, it was evidenced that time management has a positive and significant direct effect on student performance. Then, the mediating relationship was established in the model where self-efficacy was introduced as a mediator in time management and student performance relationship. Hypothetically, it is difficult to confirm the superiority of any model, so empirical testing was carried out. This study proposed a model to be empirically tested and confirmed that there are positive direct relationships between time management, selfefficacy and student performance. To achieve this objective, the PLS technique data analysis was adopted. There are a few steps that need to be evaluated. Firstly, the most accepted relationship between time management and self-efficacy is 
verified. First the direct relationship path coefficient between the time management and selfefficacy is 0.770 and is significant. Then, the relationship between time management and student performance also well supported with the direct relationship path coefficient between time management and student performance is 0.785 and is significant. After that the evaluation of mediating effect of self-efficacy on time management and student performance relationship was computed. The relationship amount between time management and student performance accounted by the mediator was $(0.785-0.558)=$ 0.212 , which represents 27.53 percent of the direct effect.

\section{Practical Implications}

The practical implications that can be drawn are to improve online distance learning students' time management. As the research showed, time management has a direct effect on students' performance mediated by self-efficacy. Secondly, online distance learning institutions should motivate students and encourage them to have their own time management in their study. Thirdly, selfefficacy should be paid attention to by online distance learning institutions.

\section{CONCLUSION}

Therefore, it is confirmed that self-efficacy is partially mediates the time management and student performance relationship. As a result, the above findings statistically justified that selfefficacy plays a role as a mediator and have mediating effect on time management and student performance relationship in Malaysian online distance learning.

\section{Research Limitations and Directions for Future Research}

Due to the nature of investigative research of this study, this paper introduce self-efficacy on online distance learning institutions student performance influential mechanism model, and carried out in the scientific and systemic empirical research, and produced firm conclusions, while it has some limitations due to research funding and ability. Therefore, some future directions should be performed. Firstly, in relation to research samples, this study only chose online distance learning institutions' students in Klang Valley areas as respondents. Also this study lacks discussions on that whether the geographical factors, as a mediating variable, will have impact on student performance. Then, on the sampling time and space, the study only obtained the latitudinal data belonging to static research. Nonetheless, if we desire to establish the causal relationships between variables, it's better to make a follow-up assessment to accumulate longitudinal data to be analyzed. Due to the above limitations, on one hand, additional research may be performed on refining our scale to obtain better internal validity. Conversely, the survey should be carried out on different types and timings to get the generic model to make the external validity better.

\section{References:}

[1] Bandura, A (1988). Organizational Application of Social Cognitive Theory. Australian Journal of Management. Vol.13 No.2, pp. 275-302.

[2] Larreamendy-Joerns, J. \& Leinhardt, G. (2006). Going the distance with online education. Review of Educational Research, Vol. 76 No. 4), 567-605. doi: 10.3102/00346543076004567

[3] Tallent-Runnels, M. K., Thomas, J. A., Lan, W. Y., Cooper, S., Ahern, T. C., Shaw, S. M., \& Liu,X.(2006). Teaching courses online: A the research. Review of Educational Research, 76(1), 93-135.doi: 10.3102/00346543076001093. [4] Bates, A. W. (2005). Technology, e-learning and distance education, (2nd ed.). New York: Routledge Falmer

[5] Rumble, G., \& Latchem, C. (2004). Organisational models for open and learning. Policy for open and distance learning. In. Perraton $\&$ H. Lentell (Eds.), Policy for open and distance learning (pp. 117-140). London: Routledge Falmer. [6] Gerard, M. (2002). Negative influences of time management. Retrieved from www.eskishore. Com/tiometips52.asp

[7] Fazal, S. (2012). The Role of Study Skills in Academic Achievement of Students: A Closer Focus on Gender. Pakistan journal of

Psychological research, Vol. 27 No. 1, pp. 3751.

[8] Agarwal, A. (2008). Self discipline for studentinfluences on time management. Retrieved August 19, 2012, from http://www.ezinarticles.com

[9] Bandura, A. (1986). Social foundations of thought action: A social cognitive theory. Englewood Cliffs, NJ: Prentice Hall.

[10] Moustafa Abd-Elmotaleb \& Sudhir K. Saha. (2013). The role of academic self-efficacy as a mediator variable between perceived academicclimate and academic performance, Journal of Education and Learning; Vol. 2 No. 3, pp. 117-129.

[11] Raafat George Saadé and Dennis Kira, (2009). Computer anxiety in e-learning: the effect of computer self-efficacy, Journal of Information Technology Education, 9, pp. 177-191.

[12] Chin, W.W. (1998a). Issues and opinion on structural equation modeling, MIS Quarterly, Vol. 22 No. 1, pp. VII-XVI.

[13] Chin, W.W. (2001). PLS-Graph user's guide version 3.0, Soft Modeling Inc. 
[14] Hayes, A. F. (2012). PROCESS: A versatile computational tool for observed variable mediation, moderation, and conditional process modeling [White paper]. URL: http://www.afhayes.com/public/process2012 .pdf (Accessed on 22.5.2012)

[15] Hair.Jr., J. F., Black., W. C., Babin., B. J., Anderson., R. E., \& L.Tatham., R. (2006). Multivariance data analysis. New Jersey: Pearson International Edition.

[16] Chin, W.W. (1998b). The partial least squares approach for structural equation modeling, in Marcoulides, G.A. (Ed.), Modern methods for business research, Lawrence Erlbaum

Associates, Mahwah, NJ.
[17] Stan, V. and Saporta, G., (2005). Conjoint use of variables clustering and PLS structural equations modelling. In PLS05, 2005. 4th Symposium on PLS and related methods, Barcelone, 7-9 September 2005.

[18] Gefen, D., Straub, D. and Boudreau, M.C. (2000). Structural equation modeling and regression: guidelines for research practice, Communications of the Association for Information Systems, Vol. 4 No. 7, pp. 1-77. 